Association for Information Systems

AIS Electronic Library (AISeL)

\title{
How Challenging is the Development of Digital Services in an Automotive Environment? An Empirical Study of the Incongruences between Business and IT Experts
}

Mirheta Omerovic Smajlovic

Technische Universität Darmstadt

Nihal Islam

Technische Universität Darmstadt

Peter Buxmann

Technische Universität Darmstadt

Smajlovic, Mirheta Omerovic; Islam, Nihal; and Buxmann, Peter, "How Challenging is the Development of Digital Services in an Automotive Environment? An Empirical Study of the Incongruences between Business and IT Experts" (2021). Wirtschaftsinformatik 2021 Proceedings. 4.

https://aisel.aisnet.org/wi2021/HDigitaltransformation17/Track17/4

This material is brought to you by the Wirtschaftsinformatik at AIS Electronic Library (AISeL). It has been accepted for inclusion in Wirtschaftsinformatik 2021 Proceedings by an authorized administrator of AIS Electronic Library (AISeL). For more information, please contact elibrary@aisnet.org. 


\title{
How Challenging is the Development of Digital Services in an Automotive Environment? An Empirical Study of the Incongruences between Business and IT Experts
}

\author{
Mirheta Omerovic Smajlovic ${ }^{1}$, Nihal Islam ${ }^{1}$, Peter Buxmann ${ }^{1}$ \\ ${ }^{1}$ Technische Universität Darmstadt, Germany \\ omerovic@is.tu-darmstadt.de, islam@is.tu-darmstadt.de, buxmann@is.tu-darmstadt.de
}

\begin{abstract}
The ongoing digitalization empowers incumbent firms on their path from mere producers into providers of holistic digital service solutions. Although digitalization offers a wide range of opportunities such as improved internal processes or new business models, it also leads to managerial and organizational challenges. To identify the cause of specific challenges in an automotive environment, we analyze the development of a digital service with a focus on the collaboration of business and IT experts in this process. Within the scope of a case study in an automotive environment and by consideration of the technological frames of references (TFR) theory as a framework, our results present relevant frame domains in which dominate incongruences between business and IT experts that consequently lead to related challenges. Our key findings and insights extend the existing research and practice related to the development of digital services in an automotive environment.
\end{abstract}

Keywords: Digital Service, Automotive Environment, Technological Frames of Reference Theory, Case Study.

\section{Introduction}

Information systems (IS) development in general and especially innovative digital services enable firms to create new business values [21] but also require them to revisit their entire organizing and managerial logic [12], [20], [36]. This particularly holds for incumbent firms, as the embedment of digital technologies forces firms to break away from established innovation paths [32-33] without jeopardizing existing product innovation practices [80], [82]. We find the automotive environment particularly interesting as the new technologies enable a wide variety of digitalization possibilities within the world of vehicles. It is now becoming possible that vehicles can communicate between themselves and with the surrounding digital environment [6-7], enabling a platform for delivering digital services [25], [70], [83]. Moreover, new competitor landscapes motivate the growing emphasis on digital transformation within the automotive industry [4]. For instance, the launch of the open car communications platform enabling third-party developers' access to multiple sensors in the vehicle was a big hit for automotive circles breaking the institutionalized tradition of in-house development [32]. In this regard, to keep the market position and compete against existing and novel digital competitors, car manufacturers are increasingly penetrating

16th International Conference on Wirtschaftsinformatik,

March 2021, Essen, Germany 
the world of software development to provide digital services in-house [45], [68], [82]. Such an insourcing process requires significant managerial and organizational changes [32-33]. For instance, a collaboration between business and IT experts acquires completely new dimensions and modes of an organization requiring "the mutual accommodation and blending of business and IT interests" [29].

The collaboration between business and IT experts is a widely discussed topic within IS research. However, most of the previous studies focus on a company-wide strategic level of alignment and as noted in Vermerris et al. (2014) [84] "it largely ignores the operational practices that help achieve alignment in IT projects". And, while there are multiple studies of IT and business collaboration and alignment at the macro strategic and structural levels [76], only a few studies are tackling the project level of analysis (e.g. [9] and [13]). Moreover, there has been an expansion in identifying and analyzing diverse aspects of the development of digital services in multiple industries (e.g. [75], [80], [88]), but there are no insights related to the specific challenges of the business and IT experts' collaboration in this new digital landscape of an established automotive environment. Since a collaboration between business and IT experts is essential for exploiting the potentials of digitalization [80], it is important to understand the challenges of the development of digital services from their perspectives. Against this background, we aim to answer the research question of what are the incongruences between business and IT experts that lead to related challenges in the development of digital services in an automotive environment. To answer this, we have analyzed the development of a digital service in the context of a case study within a globally operating car manufacturer and interviewed business and IT experts collaborating on the project. By conducting interviews $(\mathrm{N}=18)$ and data handling we sort our findings in the technological frames of reference theory (TFR) [66], which represents our theoretical lens for the data analysis. This framework helps us to investigate how the project participants perceive the project requirements [16], [26] and analyze the human sense-making processes [10], [14] as it represents a systematic approach to examine assumptions, expectations, and knowledge people have about the technology [66].

\section{Theoretical Background}

Many studies simultaneously use expressions related to digitalization. While "digitization" describes the transition from analog to digital through technology, "digitalization" includes further changes in processes. Finally, the term "digital transformation" includes all transformational processes and impacts that go beyond the business perspective, such as organizational and cultural changes [61]. In the existing literature, there are a variety of expansions in identifying and analyzing diverse facets of digital services and digital transformation. For instance, the literature on personal information disclosure [2], technology and innovation [17], governance of intellectual property [30], ecosystems [75], incumbent environments [80], and supply chain [88] show the increased interest in specific aspects related to the development of digital services. Considering these facets, the term digital service refers to utility obtained or 
arranged through a digital transaction [3], [87] where the bundling of diverse resources and IT artifacts leads to new value experiences [54], [63].

Prior researchers have dealt extensively with aspects around the business and IT collaboration and their alignment. Chan and Reich (2007) [11] provide a review of the alignment literature in IT. Gerow et al. (2014) [24] report on the development of definitions and measure six types of alignment including alignment between IT and business strategies, infrastructures, and processes, while also examining the strategies across these two domains that are linked with infrastructures and processes. Haffke and Benlian (2013) [35] demonstrate the importance of interpersonal understanding for the business and IT partnership, while Preston and Karahanna (2009) [72] draw attention to the necessity to align the organizations' IS strategy with its business strategy. Finally, Sledgianowski and Luftman (2005) [79] describe the use of a management process and assessment tool that can help to promote long-term IT-business strategic alignment. Recent studies also show that IT strategies generally focus on the internal processes and have a rather limited impact on driving innovations in business development [59], [83]. However, the role of IT is no longer to merely ensure efficient processes but also to lead innovativeness and new digital services development [37]. For decades, digitalization has led to different organizational transformations [78], but the productcentric nature of the vehicle manufacturers [42], [55] still requires major structural changes to accommodate both business and IT interests [19], [29]. IT is becoming a leading part of the business model [9], [52], [67], where different approaches to development processes of digital services and vehicle production have to integrate [71]. In order to build up such digital service competencies, vehicle manufacturers are establishing new ways of collaboration between business and IT in their value creation processes [58], [69]. Therefore, within this research work, we aim to extend and shed light on the business and IT collaboration under such new conditions. The literature on alignment has strong parallels with the TFR theory since it provides a useful analytic lens to investigate how the project participants perceive the project requirements. This theory acknowledges that different groups in a development process have different interpretations, so-called "technological frames", of the usefulness, importance, and significance of technologies. This research approach has been introduced within the IS research by Orlikowski and Gash (1994) [66] who identified three frame domains: "nature of technology", referring to the understanding of the technology's capability and functionality; "technology in use", describing the actual conditions and consequences of technology usage; and "technology strategy", which takes into account the vision of the technology value for the organization. Using the results of the empirical study where they interviewed technologists and users about the "Notes technology", Orlikowski and Gash (1994) [66] claim that the differing perspectives of these two groups onto the technology create difficulties and conflicts in the usage of the "Notes technology". The core finding of the TFR theory shows that if key groups have different perceptions within the frames the organization might experience incongruence of the frames. The incongruence leads to organizational inefficiencies. These variable "dimensions" of the TFR theory facilitate an analysis of the perspectives of business and IT experts, which are dynamic in nature [1], [53]. Many empirical studies supported the findings of Orlikowski and Gash (1994) (e.g. [38], [51], [57], 
[87]), while only a few researchers pointed out contrasting effects as well (e.g. [15], [46]). Building on the negative effects of the incongruity between the frames, many studies suggested mechanisms to overcome the misalignment between different groups such as power [14], politics [44], interaction and communication [77], exchange of knowledge [73], understanding of technology [37], tool support, and the clear defining of procedures [34].

\section{$3 \quad$ Methodology}

To address our research question about the cause of the challenges related to the development of a digital service from the business and IT experts' perspectives, we conducted an interpretive case study [90] which is well suited to explore cognitive processes behind judgments of technology [62] as well as the overall topic in-depth [23], [40], [43]. Cognitive research relies on the fundamental principle that an individual's knowledge is structured through experience and interaction [22], [28]. As a basis of an iterative process of data collection and analysis, we used the TFR theory as a framework to investigate the preconditions of challenges in a collaboration between business and IT experts [66]. In the following, the research setting and the data analysis are described in detail.

\subsection{Research Setting}

In the case study, we investigated the collaboration between business and IT experts in the development of a digital service within a large German car manufacturer (CAR AG; a pseudonym). The rationale underlying our selection of the CAR AG was influenced by the following factors: the ability to take advantage of the opportunities offered by digitalization, the rich context of related challenges due to the first-time development of a digital service, and finally the availability of information. CAR AG employs almost 300,000 employees and is one of the world's biggest manufacturers of commercial vehicles with a global reach. Their focus lies on different areas of digitalization, whose goal is to steer the change in transforming a manufacturing entity into the provider of holistic digital services and solutions. The case study we investigated focuses on the development of a digital service comprising both hardware and software in the vehicle. The hardware component acts as a host for software and services in the vehicle. The digital service acts as an open platform and can host software and services from both the CAR AG and third parties. The development of this digital service started in 2015. In the course of 2018, many other business units/departments of the CAR AG became involved in the project. The roles of the experts within each business unit/department were different, but their expertise could broadly be divided into business and IT areas. The communication between them mostly occurred on a non-regular basis. This situation and the previously described research gap inspired us to interview business and IT experts who were intensively involved in this project to see what their interpretations and perspectives related to the development of a digital service are, in order to get insights about the cause of specific challenges. 


\subsection{Data Collection and Analysis}

Our research work is based on the interpretive case study that follows the principles of planning, designing, preparing, collecting, analyzing, and sharing of data, as described in Yin (2009) [89]. The units of analysis are the business and IT experts who closely collaborate on the development of a digital service in the CAR AG. Business experts are responsible for business development (e.g. customer requirements, pricing), while IT experts take care of software and hardware development of a digital service (e.g. coding, testing). Generally, an expert is a person with special knowledge in a subject area [5]. Our primary data sources are interviews which were conducted face-to-face throughout May and June of 2019. We used a semi-structured interview guideline to minimize the bias and unstructured discussions by providing the same introductions and encouragements to each interviewee [27]. As suggested in Yin (2017) [91], the interviewee selection followed a heterogeneous purposive sample approach applying three predefined criteria: (1) interviewees are well informed; (2) their field of activity is either in a business unit or in an IT department; (3) at least three years of experience in the respective roles. In total, we carried out 18 interviews (see Table 1). Business (BU) and Information Technology (IT) experts received the same questions.

Table 1. Interviewed Experts

\begin{tabular}{|l|c|l|l|l|l|}
\hline ID & Y & Function Expertise & ID & Y & Function | Expertise \\
\hline BU1 & 4 & $\begin{array}{l}\text { Business Developer } \\
\text { Use Case Development }\end{array}$ & IT1 & 3 & $\begin{array}{l}\text { Software Developer } \\
\text { Diagnosis and Flashing }\end{array}$ \\
\hline BU2 & 5 & $\begin{array}{l}\text { Strategy Expert } \\
\text { Migration of Data }\end{array}$ & IT2 & 3 & $\begin{array}{l}\text { Software Architecture Expert } \\
\text { Device Management }\end{array}$ \\
\hline BU3 & 3 & $\begin{array}{l}\text { Sales Manager } \\
\text { Customer Acquisition }\end{array}$ & IT3 & 4 & $\begin{array}{l}\text { Software Developer } \\
\text { Prototyping }\end{array}$ \\
\hline BU4 & 3 & $\begin{array}{l}\text { Business Developer } \\
\text { Use Case Development }\end{array}$ & IT4 & 5 & $\begin{array}{l}\text { Software Developer } \\
\text { Prototyping }\end{array}$ \\
\hline BU5 & 3 & $\begin{array}{l}\text { Sales Expert } \\
\text { Use Case Development }\end{array}$ & IT5 & 5 & $\begin{array}{l}\text { Software Architecture Expert } \\
\text { Testing }\end{array}$ \\
\hline BU6 & 6 & $\begin{array}{l}\text { Service Product Owner } \\
\text { Substitution Use Case }\end{array}$ & IT6 & 3 & $\begin{array}{l}\text { IT Project Manager } \\
\text { Defining IT Requirements }\end{array}$ \\
\hline BU7 & 4 & $\begin{array}{l}\text { Sales Expert } \\
\text { Customer Requirements }\end{array}$ & IT7 & 6 & $\begin{array}{l}\text { Platform Development } \\
\text { Expert Technological Fit }\end{array}$ \\
\hline BU8 & 3 & $\begin{array}{l}\text { Business Developer } \\
\text { Use Case Development }\end{array}$ & IT8 & 4 & $\begin{array}{l}\text { IT Security Manager } \\
\text { Security Testing }\end{array}$ \\
\hline BU9 & 5 & $\begin{array}{l}\text { Strategy Expert } \\
\text { Strategy Development }\end{array}$ & IT9 & 4 & $\begin{array}{l}\text { IT Project Manager } \\
\text { Technological Feasibility }\end{array}$ \\
\hline
\end{tabular}

Table 1 shows the ID-number of the interviewees (ID), their organizational function and expertise, and years of experience (Y). Interviews lasted roughly sixty minutes and were audio-recorded. The interview guide consisted of three parts. In the first part, we collected information about the individual involvement within the project and the personal experiences of interviewees. The second part was about the business value and 
technological functionality of a digital service. In the final part, we surveyed the perceived success of the development of a digital service and influencing factors. For the conduct of the study, we took care to adhere to the seven principles of interpretive field research described by Klein and Myers (1999) [47]. In detail, our understanding of business and IT experts' perspectives as a whole is achieved through the iteration of their individual opinions, a reflection of the context of the automotive organization, and our interaction with the experts. Moreover, throughout the entire process of data analysis, we were sensitive to possible differences between theoretical preconceptions and actual findings, as well as to possible interpretation differences among experts. For the process of data analysis, we used a content data analysis [49] so that we were able to assume a broad perspective [85-86] and allow for the emergence of frame domains, but at the same time be able to identify the relations between the codes within frames and assimilations with the TFR theory. To sort and refine data categories, we first followed the open coding instructions as described in Miles et al. (1994) [60], while for the theory fit we used the TFR framework presented in Orlikowski and Gash (1994) [66]. In the first phase, we coded all statements reflecting knowledge, expectations, and assumptions creating the frame domains. Using separate code categories, we coded all statements concerning frame incongruence. Frame incongruence describes the issues arising from the existing different perspectives within the frame domains [66]. In a second phase, we integrated codes into aspects, assigned the aspects to business and IT experts, and finally compared the findings. We conducted a pattern coding where we established relations between the aspects and clustered them into the frame content domains. Although there are different views also within IT and business expert groups, for simplification reasons we represent only the homogenous views. Two coders using the qualitative data transcription and analysis software "f4" have done the coding. For each transcribed interview, codes were assigned to the opinions that were found to be most common amongst the participants by both persons separately. After a discussion between the coders, all categories are combined and marked only those that were coded by all.

\section{$4 \quad$ Empirical Results}

Since the frame domains are time and context-dependent, we followed the encouragement from Orlikowski and Gash (1994) [66] to examine them in situ, rather than priori. By coding all statements reflecting knowledge, assumptions, and expectation of business and IT experts about the development of a digital service, three frame domains emerged that led to the experts' frame incongruity:

(1) Business Values of a Digital Service refers to the business and IT experts' perspective of the digital service business potential and value;

(2) Technological Functionalities of a Digital Service refers to the perspective of the business and IT experts about its technological functionalities and;

(3) Strategy for the Development Process of a Digital Service refers to the perspective of the business and IT experts about the successful execution of the development process of a digital service. 


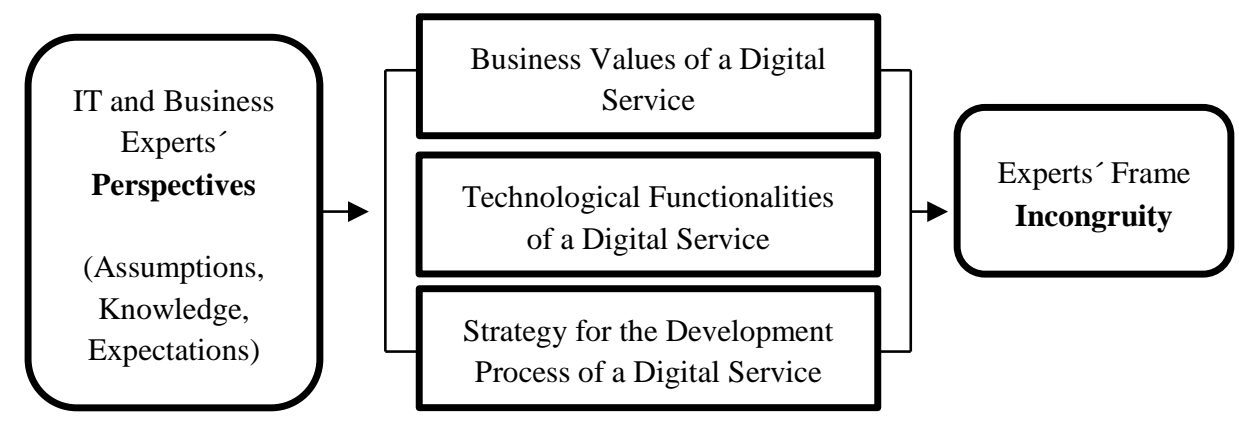

Figure 1. Frame Domains related to the Development of a Digital Service

Figure 1 illustrates the frame domains of our findings. In the following sub-chapters, we briefly describe each frame domain and list the content characteristics that were most repeated by either IT or business experts. For instance, for the frame domain "business values of a digital service", we listed the business values often mentioned by either business or IT experts. Based on how often certain aspects were mentioned, we placed the values accordingly, which were then illustrated through tables and box symbols. The white box $(\square)$ demonstrates that none of the IT or business experts mentioned a certain aspect. The white box with a little black dot inside ( $\square$ ) symbolizes that less than three experts mentioned the aspect. The black box within the white one (回) shows that between three and six of the experts mentioned it, while the black box (ם) shows that more than six of the business or IT experts mentioned it. If the values for identified characteristics are found to be different within these frame domains, we can conclude that business and IT experts possess distinct frames [66].

\subsection{Business Values of a Digital Service}

The business values of the digital service refer to the assumptions, expectations, and knowledge of the business and IT experts about the potential of the digital service to win over customers and provide positive returns for the CAR AG. Table 2 shows the identified business values of the digital service. As can be seen in Table 2, both business and IT experts agree that a great benefit of this digital service is the possibility to provide customers a platform to develop their own solutions. The following citation of one business expert exemplifies this finding: "Digital service helps us provide new innovative products or services that are beyond [the] classic automotive environment" (BU3). An IT expert also emphasized this aspect through the comment that: "Digital service has the potential to offer customized and individualized specific software adaptations" (IT4). The remaining aspects consistently differ. IT experts see prominent business value in establishing the recurring long-term payments for the digital service itself and a possibility to save on costs through the use of only one hardware for multiple digital services: "[...] we make some money by selling the hardware and then by establishing recurring payments for the service” (IT8). 
Table 2. Business Values of a Digital Service

\begin{tabular}{|c|l|c|}
\hline $\begin{array}{c}\text { Business } \\
\text { Experts }\end{array}$ & \multicolumn{1}{|c|}{ Business Values of a Digital Service } & $\begin{array}{c}\text { IT } \\
\text { Experts }\end{array}$ \\
\hline$\square$ & The digital nature of the service ensures recurring payments & $\square$ \\
\hline$\square$ & $\begin{array}{l}\text { Digital service enables the customers to develop customized } \\
\text { digital solutions }\end{array}$ & $\mathbf{\square}$ \\
\hline$\square$ & Cost efficiencies & $\square$ \\
\hline$\square$ & Digital service enables the upselling power for the vehicles & $\square$ \\
\hline
\end{tabular}

On the other hand, business experts rather focus on the short-term benefits and upselling potential for vehicles. Namely, they do not observe the digital service as a stand-alone business, but rather as the additional benefit for the vehicle customers, which will result in an increase in vehicle sales: "If we can fix this (digital) solution and the customer is satisfied, we will sell more vehicles" (BU4). These differing perspectives on the business values of the digital service relate to several issues between business and IT experts. IT experts complained about vague requirements from the business side due to different expectations related to the real value that the final service should have: "Mostly, there is a gap in how the business describes the business solution. It is never as detailed as IT needs it and this gap is huge" (IT9). On the other hand, business experts pointed out the problem of trust: "If I say that the customer is not willing to give out so much money, I would expect IT colleagues to understand this." (BU4).

\subsection{Technological Functionalities of a Digital Service}

Digital service technological functionalities refer to the perceived technological potential of a digital service regarding its software and hardware components. As Table 3 shows, IT experts seem very enthusiastic about the general-purpose nature of the digital service that allows easier development and fast prototyping. The following IT expert's quotation exemplifies this finding: "Digital service has one feature that enables me to easily make function prototypes without reinventing the new hardware platform" (IT6). Business experts, on the other hand, rather praise the customer context offered by the digital service technology. As the following quotation shows, they appreciate the power of the digital service to combine data and automate the processes for the customers: "[The] combination of the driver information, vehicle and sensors are creating the main added value for the customer" (BU2). Moreover, business experts agreed that the real capability of the digital service lies in its ability to connect different customers onto one platform, creating the ecosystem for services and customers. 
Table 3. Technological Functionalities of a Digital Service

\begin{tabular}{|c|l|c|}
\hline $\begin{array}{c}\text { Business } \\
\text { Experts }\end{array}$ & \multicolumn{1}{|c|}{ Technological Functionalities of a Digital Service } & $\begin{array}{c}\text { IT } \\
\text { Experts }\end{array}$ \\
\hline$\square$ & Decoupling car and software development & $\square$ \\
\hline$\square$ & General-purpose platform nature & $\mathbf{\square}$ \\
\hline$\square$ & Fast prototyping & $\square$ \\
\hline$\square$ & Flexibility to combine data & $\square$ \\
\hline$\square$ & Digital service as the ecosystem enabler & $\square$ \\
\hline
\end{tabular}

According to both groups of experts, these differing perspectives cause the following issues between the two groups. Business experts criticize the classical structure: "Classical set-up within the CAR AG is that you have business and IT as separate organizations and therefore it is always difficult to come to the same level of understanding about requirements and how they could be implemented" (BU6). IT experts mostly agreed on this point as summarized with the following quote: "A lot of times it is difficult to see the client behind all of it, it is abstract because that is more of a job for business experts and for us it is more technical oriented" (IT3).

\subsection{Strategy for the Development Process of a Digital Service}

This frame domain encompasses the generalized assumptions, knowledge, and expectations from the business and IT experts about how the digital service should be developed from the organizational and project management context. Table 4 shows that the business and IT experts also here have different perspectives on what might make the development of a digital service successful. Business experts believe that the following factors will make the process successful: finding the paying customer who would like to invest in the digital service and create their services, clearly defined deadlines and timelines, as well as a good strategy to overcome legal and political issues. The following business expert's quotation exemplifies some of these findings: "What matters is customer acceptance and how many devices you can bring to the field and how many paying customers you connect [with]" (BU5). In contrast to this, IT experts rather assume that the proper software development documentation and IT security of a digital service are the main issues that they have to tackle to make the process successful. The following quotation exemplifies this finding: "The security is the most critical part of the digital service because it is [...] to open up the intellectual property of the car" (IT5). 
Table 4. Strategy for the Development Process of a Digital Service

\begin{tabular}{|c|l|c|}
\hline $\begin{array}{c}\text { Business } \\
\text { Experts }\end{array}$ & \multicolumn{1}{|c|}{$\begin{array}{c}\text { Strategy for the Development Process of a Digital } \\
\text { Service }\end{array}$} & $\begin{array}{c}\text { IT } \\
\text { Experts }\end{array}$ \\
\hline $\mathbf{\square}$ & Ensuring the technological stability of the digital service & $\mathbf{\square}$ \\
\hline $\mathbf{\square}$ & Finding paying customers & $\square$ \\
\hline$\square$ & Design a proper software development documentation & $\mathbf{\square}$ \\
\hline$\square$ & Formulating clear and aligned timelines of the process & $\square$ \\
\hline$\square$ & Exploring the tactics to overcome legal and political issues & $\square$ \\
\hline$\square$ & Overcoming conflicting political environments & $\square$ \\
\hline$\square$ & Ensuring the IT security of the digital service & $\square$ \\
\hline
\end{tabular}

However, both business and IT experts agree that the technological stability of a digital service is a crucial prerequisite for the successful execution of the process. Differing perspectives of business and IT experts about the strategy relate to the lack of communication in the process. As the following quotations show, both business and IT experts feel there is miscommunication between them: "There is a big language barrier [...] and therefore, there is a lack of communication" (IT8). In another interview, we noted a similar view: "These IT experts [...] have been recently hired and they define their own processes, but they do not fit into the processes of CAR AG and therefore, there is the lack of understanding" (BU9).

\section{Discussion}

Based on the approach of the TFR theory, we illustrate that business and IT experts hold different perspectives on (1) business values, (2) technological functionalities, as well as the (3) strategy for the development process of a digital service.

Firstly, when it comes to the "business values of a digital service" frame domain, we found that IT experts perceive a digital service as a completely new business model, which might enable recurring payments and a long-term relationship with a customer (e.g. "[...] we make some money by selling the hardware and then by establishing recurring payments for the service” (IT8)). On the other hand, business experts appreciate the upselling value for vehicles that the digital service might provide (e.g. "If we can fix this (digital) solution and the customer is satisfied, we will sell more vehicles" (BU4)). This key finding shows the orientation of IT experts towards a digital service as a business per-se, while business experts still observe it as an additional service that comes on top of vehicle sales. In particular, while IT experts would like to focus on the long-term benefits of the new digital service, business stakeholders rather appreciate short-term positive returns through the increased number of sold vehicles. This sort of different practice philosophies and ambidexterity of a development process cause particular challenges between IT and business experts in the development of digital services within automotive organizations (e.g. lack of trust, vague requirements) [74], [92]. Therefore, there is a necessity to balance between the long-term and short- 
term demands of a market by providing digital services that enable both recurring payments and short-term upselling power for the vehicles.

Secondly, regarding the "technological functionalities of a digital service" frame domain, IT experts perceive the general-purpose nature as one of the most compelling technological functionalities of the digital service (e.g. "Digital service has one feature that enables me to easily make function prototypes without reinventing the new hardware platform" (IT6)). In contrast, business experts put a stronger emphasis on the flexibility to combine data (e.g. " [The] combination of the driver information, vehicle and sensors is creating the main added value for the customer" (BU2)). This key finding is in line with existing research, which confirms that IT experts have a more engineering perspective [56], [65] while business experts have rather a strategic understanding of technology [39], [66]. Further key findings in this frame domain show that such differing perspectives relate to the classical divisional structure between business and IT, which still exist within incumbent automotive environments. Such separation leads to a vague definition of requirements for the development process. However, for the progress and success in developing a digital service, it is necessary that all stakeholders previously agree on what needs to be accomplished and how [31]. In our view, incumbent firms in an automotive environment must rethink their existing organizational structures of business and IT departments where research could play a crucial role in providing suitable options and possibilities. Against this background, in IS research we need more studies that investigate the organizational setups suitable to incorporate 'old' and 'new' functionalities into their structure in a complementary and not impeding way [48], [50]. For this purpose, incumbent firms in an automotive environment need to reflect on the talents and skills of experts because such a new environment seeks employees who are able to integrate digital technology expertise with business knowledge and vice versa [71].

Thirdly, the "strategy for the development process of a digital service" frame domain shows that IT experts put a great emphasis on the existence of good software development documentation and IT security of the digital service (e.g. "The IT security is the most critical part of a digital service because it is a very big challenge to open up the intellectual property of the car" (IT5)). Yet, business experts see the challenges related to the politics and legal issues, as well as the necessity to find a paying customer as crucial factors to succeed in this project (e.g. "What matters is customer acceptance and how many devices you can bring to the field and how many paying customers you connect [with]" (BU5)). To align these perspectives, existing IS research has shown that business and IT planning must integrate to ensure the implementation of business objectives in both IT and business planning and operations [8], [39]. The differences here relate to the fact that business experts believe that recently employed IT experts should adhere to existing processes and structures within a long-existing automotive environment. The expectation that IT experts should simply integrate into existing processes and structures is an interesting finding. In our view, for the successful process execution, there is a need for both sides to compromise. As the findings of Sklyar et al. 2019 [81] have recently shown, the development of digital services cannot rely on the old-fashioned centralized style of the organization, but requires greater integration between central structure and units implementing the projects. 


\section{Conclusion}

Our study aimed to identify incongruences between business and IT experts in order to be able to create clarity on the specific challenges in the development of digital services. Against this background, we investigated the collaboration between business and IT experts working on the development of a digital service within the automotive manufacturer. Based on the TFR theory, we have found three frame domains that lead to incongruence on the part of business and IT experts. Thereby, the business and IT experts' misalignments represent a real challenge in successfully developing digital services. For instance, we previously described how business and IT experts perceive the business model behind a digital service differently. While IT experts see it as a business per se with possible long-term recurring payments, business experts rather emphasize the potential to improve the sales of the vehicles. This incongruence might lead to multiple issues such as a lack of trust or misunderstanding. Therefore, in practice, when managers are in charge of projects where both business and IT expertise are needed, we highly recommend these managers to understand the framing logic and to examine if business and IT experts have similar views on the vision, objectives, and values of a digital service. Moreover, since both expert groups relate the existence of different perspectives in the technological functionalities of a digital service mostly to the existing traditional structures of automotive organizations, the current organization and the division of the business and IT units should be challenged. The identified frame incongruences between business and IT experts might help automotive organizations to organize their business and IT teams more effectively.

Regarding the implications for research, we extended the knowledge about specific challenges based on the TFR theory. Many studies used the concept of the TFR theory as a framework, but to the best of our knowledge, all of the empirically studied technologies applied for the improvement of internal processes and organization (e.g. [14], [51], [57]). With our study, we firstly introduced novel technological frames related to the development of a digital service within an incumbent firm in an automotive environment, and secondly, showed the applicability of the theory for the technologies meant for the external customers of the organization [64]. Thereby, we focused on the business-centric perspective where the scope lies within the digital service at the interface of customers and not the improvement of internal processes [59]. Thus, we were able to specify and extend the knowledge on framing processes applying the TFR theory in the context of internal development for external customers. We, therefore, demonstrated the usability of this theory for any organizational environment operating in similar circumstances. Furthermore, as IT becomes the leading part of the business model and strategy [18], [41], digital transformation in incumbent firms requires the establishment of new ways of collaboration between business and IT in their value creation processes [58]. To meet the challenges of digitalization, IT functions search for new modes of organizations and forms of collaboration and alignment with the business departments [51]. Given the increasing relevance of digitalization in firms, research on success factors and identifying organizational and managerial challenges of the digital services development within traditional structures is of great importance for IS research and practice. 
However, our study comes with certain limitations. Due to the interpretive nature of the research, results represent the sense-making process of the researchers. Moreover, our study focused on the development of digital service from the perspective of the business and IT experts while investigating the process of digital product development from the top management level. This could have given different results because they have a cross-process view. Finally, the case study and interpretive research are limited in generalizability. Since the identified aspects related to the frame domains of our case study are based on an automotive environment, the findings might be too specific. Nevertheless, the framing structure is of a more general nature that facilitates the formations of judgments for the research. For future research, a longitudinal analysis of framing processes could be useful in order to figure out the details and to extend the identified effects.

\section{References}

1. Allen, J. P., \& Kim, J. 2005. IT and the video game industry: tensions and mutual shaping. Journal of Information Technology, 20(4), 234-244.

2. Anderson, C. L., and Agarwal, R. 2011. The Digitization of Healthcare: Boundary Risks, Emotion, and Consumer Willingness to Disclose Personal Health Information. Information Systems Research (22:3), pp. 469-490.

3. Athanasopoulou, A., Bouwman, W. A. G. A., Nikayin, F. A., \& de Reuver, G. A. 2016. The disruptive impact of digitalization on the automotive ecosystem: a research agenda on business models, platforms and consumer issues. The 29th Bled eConference: Digital economy.

4. Battleson, D. A., West, B. C., Kim, J., Ramesh, B., \& Robinson, P. S. 2016. Achieving dynamic capabilities with cloud computing: an empirical investigation. European Journal of Information Systems, 25(3), 209-230.

5. Bogner, A., Littig, B. and Menz, W. eds., 2009. Interviewing experts. Springer.

6. Brookes, Richard, and Patricio Pagani. 2014. What becomes a car. Proposed Paper for: BIT 2014 Conference Workshop-Technology Enabled Business Models: Platforms, Analytics and Performance.

7. Broy, M., Kruger, I. H., Pretschner, A., \& Salzmann, C. 2007. Engineering automotive software. Proceedings of the IEEE, 95(2), 356-373.

8. Birchmeier, Z. P. 2004. Exploring the conditional benefits of team diversity: The interaction of task requirements and team composition on tacit coordination efficiency (Doctoral dissertation).

9. Campbell, B. R. 2005. Alignment: Resolving ambiguity within bounded choices. In Pacific Asia Conference on Information Systems. University of Hong Kong.

10. Cenfetelli, Ronald. 2004. Inhibitors and Enablers as Dual Factor Concepts in Technology Usage. In: JAIS 5 (11), S. 472-492. DOI: 10.17705/1jais.00059.

11. Chan, Y. E., \& Reich, B. H. 2007. IT alignment: what have we learned? Journal of Information technology, 22(4), 297-315.

12. Chanias, S., \& Hess, T. 2016. Understanding Digital Transformation Strategy formation: Insights from Europe's Automotive Industry. In PACIS.

13. Cragg, P., King, M. and Hussin, H., 2002. IT alignment and firm performance in small manufacturing firms. The Journal of Strategic Information Systems, 11(2), pp.109-132. 
14. Davidson, E. J. 2002. Technology frames and framing: A socio-cognitive investigation of requirements determination. MIS Quarterly, 329-358.

15. Davidson, R. J. 2000. Affective style, psychopathology, and resilience: brain mechanisms and plasticity. American Psychologist, 55(11), 1196.

16. Davidson, E. 2006. A technological frames perspective on information technology and organizational change. The journal of applied behavioral science, 42(1), 23-39.

17. Dougherty, D., and Dunne, D. D. 2012. Digital Science and Knowledge Boundaries in Complex Innovation. Organization Science (23:5), pp. 1467-1484.

18. Dijkman, R. M., Sprenkels, B., Peeters, T., \& Janssen, A. 2015. Business models for the Internet of Things. International Journal of Information Management, 35(6), 672-678.

19. Delaney Kevin and Levy Eran. 2017. Internet of Things: Challenges, Breakthroughs and Best Practices. Cisco Report.

20. Firnkorn, J., \& Müller, M. 2012. Selling mobility instead of cars: new business strategies of automakers and the impact on private vehicle holding. Business Strategy and the environment, 21(4).

21. Fichman, R. G., Dos Santos, B. L., \& Zheng, Z. E. 2014. Digital innovation as a fundamental and powerful concept in the information systems curriculum. MIS Quarterly, 38(2).

22. Fiol, C. 1994. Consensus, Diversity, and Learning in Organizations. Organization Science.

23. Flynn, D., \& Du, Y. 2012. A case study of the legitimation process undertaken to gain support for an information system in a Chinese university. European Journal of Information Systems, 21(3).

24. Gerow, J.E., Thatcher, J.B. and Grover, V. 2014. Six Types of IT-Business Strategic Alignment: An investigation of the constructs and their measurement, European Journal of Information Systems 24(3): 1-27.

25. Golestan, K., Sattar, F., Karray, F., Kamel, M., \& Seifzadeh, S. 2015. Localization in vehicular ad hoc networks using data fusion and V2V communication. Computer Communications, 71, 61-72.

26. Goes, P. 2013. Editor's Comments: Information Systems Research and Behavioral Economics. MIS Quarterly, 37 (3), iii-viii.

27. Gibbert, M., Ruigrok, W., \& Wicki, B. 2008. What passes as a rigorous case study? Strategic management journal, 29(13), 1465-1474.

28. Griffith, T. L. 1999. Technology features as triggers for sensemaking. Academy of Management review, 24(3), 472-488.

29. Gregory, R. W., Keil, M., Muntermann, J., \& Mähring, M. 2015. Paradoxes and the nature of ambidexterity in IT transformation programs. Information Systems Research, 26(1).

30. Greenstein, S., Lerner, J., and Stern, S. 2013. Digitization, Innovation, and Copyright: What Is the Agenda?. Strategic Organization (11:1), pp. 110-121.

31. Gilchrist, A., Burton-Jones, A. and Green, P., 2018. The process of social alignment and misalignment within a complex IT project. International Journal of Project Management, 36(6), pp.845-860.

32. Henfridsson, O., Mathiassen, L., and Svahn, F. 2014. Managing Technological Change in the Digital Age: The Role of Architectural Frames. Journal of Information Technology.

33. Henfridsson, O., and Yoo, Y. 2014. The Liminality of Trajectory Shifts in Institutional Entrepreneurship. Organization Science (25:3), pp. 932-950.

34. Harnisch, S., Kaiser, J., \& Buxmann, P. 2013. Technological Frames of Reference in Software Acquisition Decisions: Results of a multiple case study.

35. Haffke, I. and Benlian, A., 2013. To understand or to be understood? A dyadic analysis of perceptual congruence and interdependence between CEOs and CIOs. Darmstadt Technical University, Department of Business Administration, Economics and Law. 
36. Hanelt, A., Piccinini, E. Gregory, R. Hildebrandt, B. \& Kolbe, L. 2015. Digital Transformation of preliminary Industries. Exploring the impact of Digital trends on business Models of Automobile Manufacturers. Proceedings of the 12th Internationalen Tagung Wirtschaftsinformatik. Osnabrück.

37. Horlach, B., Drews, P. and Schirmer, I., 2016. Bimodal IT: Business-IT alignment in the age of digital transformation. Multikonferenz Wirtschaftsinformatik (MKWI).

38. Hsu, C. W. 2009. Frame misalignment: interpreting the implementation of information systems security certification in an organization. European Journal of Information Systems.

39. Huang, C. D., \& Hu, Q. 2007. Achieving Business - IT strategic alignment via enterprisewide implementation of balanced scorecards. Information Systems Management, 24(2).

40. Huang, P. Y., Pan, S. L., \& Ouyang, T. H. 2014. Developing information processing capability for operational agility: implications from a Chinese manufacturer. European Journal of Information Systems, 23(4), 462-480.

41. Islam, N.; Buxmann, P.; Eling, N. 2017. Why should Incumbent Firms jump on the Start-up Bandwagon in the Digital Era? - A Qualitative Study, in Leimeister, J.M.; Brenner, W. (Hrsg.): Proceedings der 13. Internationalen Tagung Wirtschaftsinformatik (WI 2017), St. Gallen, S. 1378-1392

42. Juehling, E., Torney, M., Herrmann, C. and Droeder, K., 2010. Integration of automotive service and technology strategies. CIRP Journal of Manufacturing Science and Technology.

43. Kaiser, J., \& Buxmann, P. 2012. Organizational design of IT supplier relationship management: a multiple case study of five client companies. Journal of Information Technology, 27(1), 57-73.

44. Kandathil, G., Wagner, E. L., \& Newell, S. 2011. Translating es-embedded institutional logics through technological framing: an Indian-based case example. In ECIS (p. 47).

45. Kyriazis, D., \& Varvarigou, T. 2013. Smart, autonomous and reliable Internet of Things. Procedia Computer Science, 21, 442-448.

46. Kilduff, M., Angelmar, R., \& Mehra, A. 2000. Top management-team diversity and firm performance: Examining the role of cognitions. Organization science, 11(1), 21-34.

47. Klein, H. K., \& Myers, M. D. 1999. A set of principles for conducting and evaluating interpretive field studies in information systems. MIS Quarterly, 23(1), 67-94.

48. Kohli, R., \& Melville, N. P. 2020. Digital innovation: A review and synthesis. Information Systems Journal, 29(1), 200-223.

49. Lacity, M. C., \& Janson, M. A. 1994. Understanding qualitative data: A framework of text analysis methods. Journal of Management Information Systems, 11(2), 137-155.

50. Legner, C., Eymann, T., Hess, T., Matt, C., Böhmann, T., Drews, P. \& Ahlemann, F. 2017. Digitalization: opportunity and challenge for the business and information systems engineering community. Business $\&$ information systems engineering.

51. Lin, A., \& Silva, L. 2005. The social and political construction of technological frames. European Journal of Information Systems, 14(1), 49-59.

52. Lindgren, R., Andersson, M., and Henfridsson, O. 2008. Multi-Contextuality in BoundarySpanning Practices. Information Systems Journal (18:6), pp. 641-661.

53. Luftman, J., \& Brier, T. 1999. Achieving and sustaining business - IT alignment. California management review, 42(1), 109-122.

54. Lusch, R.F. and Nambisan, S., 2015. Service innovation: A service-dominant logic perspective. MIS Quarterly, 39(1), pp.155-176.

55. Mahut, F., Daaboul, J., Bricogne, M., \& Eynard, B. 2015. Survey on Product-Service System applications in the automotive industry. IFAC-PapersOnLine, 48(3), 840-847.

56. Markus, M. L., \& Bjørn-Andersen, N. 1987. Power over users: its exercise by system professionals. Commun. ACM, 30(6), 498-504. 
57. Mathieu, J. E., Heffner, T. S., Goodwin, G. F., Salas, E., \& Cannon-Bowers, J. A. 2000. The influence of shared mental models on team process and performance. Journal of applied psychology.

58. Matthies, B. D., D'Amato, D., Berghäll, S., Ekholm, T., Hoen, H. F., Holopainen, J. \& Valsta, L. 2016. An ecosystem service-dominant logic - integrating the ecosystem service approach and the service-dominant logic. Journal of Cleaner Production, 124, 51-64.

59. Matt, C., Hess, T. and Benlian, A. 2015. Digital transformation strategies. Business \& Information Systems Engineering.

60. Miles, M. B., Huberman, A. M., Huberman, M. A., \& Huberman, M. 1994. Qualitative data analysis: An expanded sourcebook.

61. Mergel, I., Edelmann, N. and Haug, N., 2019. Defining digital transformation: Results from expert interviews. Government Information Quarterly, 36(4), p.101385.

62. Nardon, L., \& Aten, K. 2012. Valuing virtual worlds: The role of categorization in technology assessment. Journal of the Association for Information Systems, 13(10), 4.

63. Nambisan, S., Lyytinen, K., Majchrzak, A. and Song, M., 2017. Digital Innovation Management: Reinventing innovation management research in a digital world. MIS Quarterly, 41(1).

64. Nambisan, S. 2013. Information Technology and Product/Service Innovation: A Brief Assessment and Some Suggestions for Future Research. Journal of the Association for Information Systems (14:4), pp. 215-226

65. Orlikowski, W. J. 1988. Computer technology in organizations: some critical notes. In New technology and the labour process (pp. 20-49). Palgrave Macmillan, London.

66. Orlikowski, W. J., \& Gash, D. C. 1994. Technological frames: making sense of information technology in organizations. ACM Transactions on Information Systems (TOIS), 12(2).

67. Omerović M., Islam N., and Buxmann P. 2020. Unlashing the next wave of business models in the internet of things era: A systematic literature review and new perspectives for a research agenda. Proceedings of the 53rd Hawaii International Conference on System Sciences, 2020.

68. Porter, M. E., \& Heppelmann, J. E. 2014. How smart, connected products are transforming competition. Harvard business review, 92(11), 64-88.

69. Pagoropoulos, A., Maier, A., \& McAloone, T. C. 2017. Assessing transformational change from institutionalizing digital capabilities on implementation and development of ProductService Systems: Learnings from the maritime industry. Journal of cleaner production, 166.

70. Pillmann, J., Wietfeld, C., Zarcula, A., Raugust, T., \& Alonso, D. C. 2017. Novel common vehicle information model (cvim) for future automotive vehicle big data marketplaces. In 2017 IEEE Intelligent Vehicles Symposium (IV).

71. Piccinini, E., Hanelt, A., Gregory, R., \& Kolbe, L. 2015. Transforming industrial business: the impact of digital transformation on automotive organizations. Thirty-Sixth International Conference on Information Systems, Fort Worth 2015.

72. Preston, D. and Karahanna, E., 2009. How to develop a shared vision: The key to IS strategic alignment. MIS Quarterly Executive, 8(1).

73. Robey, D., \& Sahay, S. 1996. Transforming work through information technology: A comparative case study of geographic information systems in county government. Information systems research.

74. Reich, B. H., \& Benbasat, I. 2000. Factors that influence the social dimension of alignment between business and information technology objectives. MIS Quarterly, 81-113.

75. Riasanow, T., Galic, G., \& Böhm, M. 2017. Digital Transformation in the Automotive Industry: Towards a Generic Value Network. In 25th European Conference on Information Systems (ECIS). 
76. Reynolds, P. and Yetton, P., 2015. Aligning business and IT strategies in multi-business organizations. Journal of Information Technology, 30(2), pp.101-118.

77. Sarker, Nicholson, D. B., \& Joshi, K. D. 2005. Knowledge transfer in virtual systems development teams: An exploratory study of four key enablers. IEEE transactions on professional communication, 48(2), 201-218.

78. Scott Morton, M.S., 1991. The corporation of the 1990s: Information technology and organizational transformation. Sloan School of Management, Oxford University Press.

79. Sledgianowski, D., \& Luftman, J. 2005. Business - IT strategic alignment maturity: A case study. Journal of Cases on Information Technology (JCIT), 7(2), 102-120.

80. Svahn, F., Mathiassen, L. and Lindgren, R., 2017. Embracing Digital Innovation in Incumbent Firms: How Volvo Cars Managed Competing Concerns. MIS Quarterly, 41(1).

81. Sklyar, A., Kowalkowski, C., Tronvoll, B. and Sörhammar, D., 2019. Organizing for digital servitization: A service ecosystem perspective. Journal of Business Research.

82. Tiwana, A., Konsynski, B., and Bush, A. 2010. Platform Evolution: Coevolution of Platform Architecture, Governance, and Environmental Dynamics. Information Systems Research (21:4), pp. 675-687.

83. Venkatesh, V., Thong, J. and Xu, X. 2012. Consumer Acceptance and Use of Information Technology: Extending the Unified Theory of Acceptance and Use of Technology. MIS Quarterly, 36 (1), 157-178.

84. Vermerris, A., Mocker, M. and Van Heck, E., 2014. No time to waste: the role of timing and complementarity of alignment practices in creating business value in IT projects. European Journal of Information Systems, 23(6), pp.629-654.

85. Walsham, G. 2006. Doing interpretive research. European journal of information systems.

86. Walsham, G. 1995. Interpretive case studies in IS research: nature and method. European Journal of information systems, 4(2), 74-81.

87. Williams, K., Chatterjee, S., \& Rossi, M. 2008. Design of emerging digital services: a taxonomy. European journal of information systems, 17(5), 505-517.

88. Xue, L., Zhang, C., Ling, H., and Zhao, X. 2013. Risk Mitigation in Supply Chain Digitization: System Modularity and Information Technology Governance. Journal of Management Information Systems (30:1), pp. 325-352.

89. Yin, R. K. 2009. Case Study Research: Design and Methods. In Essential guide to qualitative methods in organizational research (Vol. 24).

90. Yin, R. K. 1989. Research design issues in using the case study method to study management information systems. The information systems research challenge: Qualitative research methods, 1, 1-6.

91. Yin, R. K. 2017. Case study research and applications: Design and methods. Sage publications.

92. Yoo, Y.J., Henfridsson, O., and Lyytinen, K. 2010. The New Organizing Logic of Digital Innovation: An Agenda for Information Systems Research. Information Systems Research. 